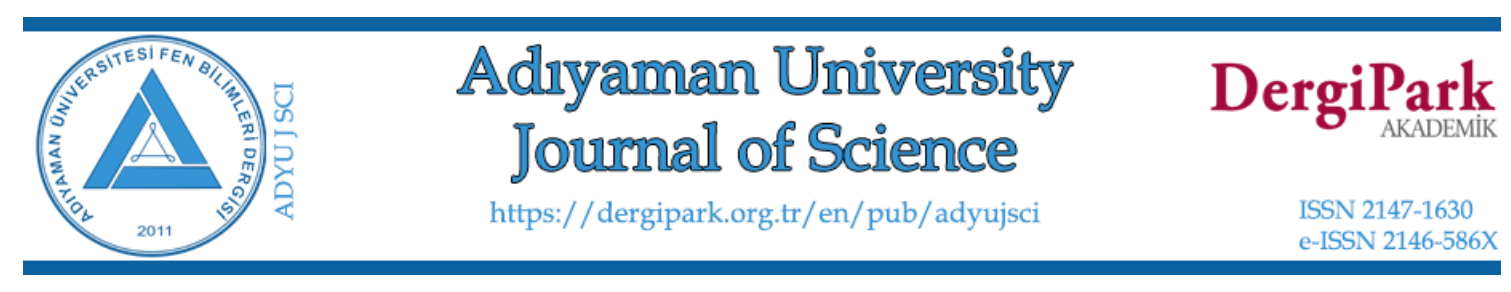

\title{
Investigation of Analytical Solutions of the Nonlinear Mathematical Model
}

\section{Representing Gas Overflowing}

\author{
Tolga AKTÜRK ${ }^{1, *}$, Yusuf GÜREFE ${ }^{2}$
}

${ }^{I}$ Ordu University, Faculty of Education, Department of Mathematics and Science Education, Ordu, Turkey

tolgaakturk@odu.edu.tr,ORCID: 0000-0002-8873-0424

${ }^{2} U$ şsak University, Faculty of Economics and Administrative Sciences, Department of Econometrics, Uşak, Turkey

ygurefe@gmail.com, ORCID: 0000-0002-7210-5683

Received: 26.01 .2021

Accepted: 28.05 .2021

Published: 30.06 .2021

\begin{abstract}
In this study, traveling wave soliton solutions of hyperbolic and trigonometric functions are successfully obtained by using the modified exponential function method of the BuckleyLeverett equation. In addition to these, there are also rational function solutions. Two and threedimensional graphs of real and imaginary parts are included with contour simulations to physically analysis of the solution functions of the equation analyzed as a mathematical model using Mathematica software.
\end{abstract}

Keywords: Buckley-Leverett Equation; Traveling wave solution; Modified exponential function method.

\section{Gaz Taşmasını Temsil Eden Doğrusal Olmayan Matematiksel Modelin Analitik Çözümlerinin Araştırılması}

Öz

* Corresponding Author

DOI: 10.37094/adyujsci.868800 
$\mathrm{Bu}$ çalışmada, modifiye edilmiş üstel fonksiyon metodu kullanılarak Buckley-Leverett denkleminin hiperbolik ve trigonometrik fonksiyon gezici dalga soliton çözümleri başarıyla elde edilmiştir. Bunların yanı sıra rasyonel fonksiyon çözümleri de elde edilmiştir. Matematiksel model olarak incelenen denklemin çözüm fonksiyonlarını fiziksel olarak analiz etmek için Mathematica yazılımı kullanılarak kontur simülasyonları ile birlikte gerçek ve sanal parçaların iki ve üç boyutlu grafiklerine yer verilmiştir.

Anahtar Kelimeler: Buckley-Leverett denklemi; Yürüyen dalga çözümleri; Geliştirilmiş Üstel Fonksiyon Metodu.

\section{Introduction}

Nonlinear partial differential equations have an important place in all areas of life. This equation is based on the motion, density, fluidity of behavior or object in fields such as physics, chemistry, engineering, health, biology, etc. It provides the opportunity to evaluate. It is essential to obtain analytical solutions to such mathematical models. Because, with the solutions of these types of mathematical models, it will be easier to evaluate the physical conditions of the object being investigated in the desired time interval. For example, various mathematical models have been developed for the Covid-19 outbreak, which has affected worldwide recently. With the help of these models, obtaining information about the course of the epidemic in advance has emerged. For this reason, there are various methods or techniques in the literature about establishing such mathematical models and analyzing their solutions [1-14].

This article aims to obtain the analytical solution or solutions of the Buckley-Leverett equation with the help of the modified exponential function method (MEFM) by determining the appropriate parameters for gas flooding under varying constant pressure boundary conditions [15]. The Buckley-Leverett equation analyzed in the article is as follows [16-18],

$$
U_{t}+\left(U-U^{3}\right)_{x}=\beta U_{x x}+\alpha U_{x x t}
$$

\section{Analysis of Modified Exponential Function Method (MEFM)}

In this section, general information about MEFM is given as follows. According to the method, the general form of the analyzed nonlinear partial differential equation is as follows;

$$
P\left(U, U^{3}, U_{x}, U_{t}, U_{x x}, U_{x x t}, \cdots\right)=0
$$

where $U=U(x, t)$, is unknown function. 
Step 1. If the following nonlinear wave transformation is applied to partial differential equations representing the mathematical model;

$$
U(x, t)=u(\xi), \xi=k \cdot(x-c t),
$$

$c$ and $k$ are real values that are not zero. The $k$ term in wave transformation represents the height of the wave, and $c$ represents the frequency of the wave. If the required derivative terms in Eqn. (1) are obtained from the wave transform Eqn. (3) and replaced by the following, the following nonlinear ordinary differential equation is obtained,

$$
N\left(u, u^{\prime}, u^{\prime \prime}, \cdots\right)=0
$$

Step 2: The solution function $U$ analyzed in the Eqn. (4) obtained above is as follows;

$$
U(\xi)=\frac{\sum_{i=0}^{n} A_{i}[\exp (-\Omega(\xi))]^{i}}{\sum_{j=0}^{m} B_{j}[\exp (-\Omega(\xi))]^{j}}=\frac{A_{0}+A_{1} \exp (-\Omega)+\cdots+A_{n} \exp (n(-\Omega))}{B_{0}+B_{1} \exp (-\Omega)+\cdots+B_{m} \exp (m(-\Omega))},
$$

where $A_{i} \neq 0,(0 \leq i \leq n)$ and $B_{j} \neq 0,(0 \leq j \leq m)$ are real and complex constants. The term $\Omega=\Omega(\xi)$ given above provides the following differential equation,

$$
\Omega^{\prime}(\xi)=\exp (-\Omega(\xi))+\mu \exp (\Omega(\xi))+\lambda
$$

If Eqn. (6) is solved under the following conditions [19],

Family 1: If $\mu \neq 0, \lambda^{2}-4 \mu>0$,

$$
\Omega(\xi)=\ln \left(\frac{-\sqrt{\lambda^{2}-4 \mu}}{2 \mu} \tanh \left(\frac{\sqrt{\lambda^{2}-4 \mu}}{2}(\xi+E)\right)-\frac{\lambda}{2 \mu}\right)
$$

Family 2: If $\mu \neq 0, \lambda^{2}-4 \mu<0$,

$$
\Omega(\xi)=\ln \left(\frac{\sqrt{-\lambda^{2}+4 \mu}}{2 \mu} \tan \left(\frac{\sqrt{-\lambda^{2}+4 \mu}}{2}(\xi+E)\right)-\frac{\lambda}{2 \mu}\right) .
$$

Family 3: If $\mu=0, \lambda \neq 0$ and $\lambda^{2}-4 \mu>0$,

$$
\Omega(\xi)=-\ln \left(\frac{\lambda}{\exp (\lambda(\xi+E))-1}\right)
$$


Family 4 : If $\mu \neq 0, \lambda \neq 0$ and $\lambda^{2}-4 \mu=0$,

$$
\Omega(\xi)=\ln \left(-\frac{2 \lambda(\xi+E)+4}{\lambda^{2}(\xi+E)}\right) .
$$

Family 5: If $\mu=0, \lambda=0$ and $\lambda^{2}-4 \mu=0$,

$$
\Omega(\xi)=\ln (\xi+E) .
$$

Step 3: Using the wave transformation, the equation obtained by substituting the required terms in Eqn. (2) is found in the algebraic equation system according to the powers of $\Omega(\xi)$. With the solving of this algebraic equation system, the values of the constants used in the solution function are obtained.

\section{Application of Modified Exponential Function Method to Buckley-Leverett}

\section{Equation}

In this section, wave solutions of the Buckley-Leverett equation are obtained through using MEFM. For this, first of all, for Eqn. (1), the wave transformation Eqn. (3) is used to find the nonlinear ordinary differential equation given below,

$$
(1-c) u-u^{3}-\beta k u^{\prime}+\alpha c k^{2} u^{\prime \prime}=0 .
$$

Considering the balancing procedure for Eqn. (12), the following equation is obtained regarding the upper limits of the symbols of the sum in Eqn. (5):

$$
n=m+1 \text {. }
$$

According to the equation obtained above, $n=2$ for $m=1$. In this case, Eqn. (5) and its derivatives terms,

$$
\begin{aligned}
& u(\xi)=\frac{\psi}{\varphi}=\frac{A_{0}+A_{1} e^{-\Omega(\xi)}+A_{2} e^{-2 \Omega(\xi)}}{B_{0}+B_{1} e^{-\Omega(\xi)}}, \\
& u^{\prime}(\xi)=\frac{\psi^{\prime} \varphi-\psi \varphi^{\prime}}{\varphi^{2}}, \\
& u^{\prime \prime}(\xi)=\frac{\psi^{\prime \prime} \varphi^{3}-\varphi^{2} \psi^{\prime} \varphi^{\prime}-\left(\psi \varphi^{\prime \prime}+\psi^{\prime} \varphi^{\prime}\right) \varphi^{2}+2\left(\psi^{\prime}\right)^{2} \psi \varphi}{\varphi^{4}},
\end{aligned}
$$

are obtained. By replacing Eqn. (13) in Eqn. (12), the $U$ solution function that provides the nonlinear ordinary differential equation is obtained. It is checked that the solution function found 
with the help of Mathematica software provides Eqn. (1). By determining the appropriate parameters, two and three-dimensional graphs of the solution function are obtained with the help of the same program.

CASE 1:

$$
\begin{aligned}
& A_{0}=\frac{1}{2} i \sqrt{-1+c-8 c k^{2} \alpha \mu} B_{0}-\frac{1}{2} \sqrt{-(-1+c) B_{0}^{2}}, \\
& , A_{1}=\frac{-4 c k^{2} \alpha B_{0}^{2}+A_{2}\left(-i \sqrt{-1+c-8 c k^{2} \alpha \mu B_{0}}+\sqrt{-(-1+c) B_{0}^{2}}\right)}{2 \sqrt{2} \sqrt{c} k \sqrt{\alpha} B_{0}}, \\
& , B_{1}=-\frac{A_{2}}{\sqrt{2} \sqrt{c} k \sqrt{\alpha}}, \beta=\frac{3 \sqrt{c} \sqrt{\alpha} \sqrt{-(-1+c) B_{0}^{2}}}{\sqrt{2} B_{0}}, \lambda=-\frac{i \sqrt{-1+c-8 c k^{2} \alpha \mu}}{\sqrt{2} \sqrt{c} k \sqrt{\alpha}} .
\end{aligned}
$$

If the coefficients given above are used, the following solution functions are obtained.

\section{Family 1:}

$$
U_{1,1}(x, t)=\frac{1}{2} \frac{\left.\left(\begin{array}{l}
-\frac{\sqrt{-(-1+c) B_{0}^{2}}}{B_{0}}+\left(\begin{array}{l}
\zeta \lambda \mu+i \sqrt{-1+c-8 c k^{2} \alpha \mu} \\
\left(4 \mu+\left(\lambda^{2}-4 \mu\right) \operatorname{Sech} \omega^{2}\right)
\end{array}\right) \\
-\zeta \sqrt{\lambda^{2}-4 \mu} \mu \operatorname{Tanh} \omega
\end{array}\right)\right)}{\left(4 \mu+\left(\lambda^{2}-4 \mu\right) \operatorname{Sech} \omega^{2}\right)},
$$

where $\omega(x, t)=\left[\frac{1}{2}(E E+\xi) \sqrt{\lambda^{2}-4 \mu}\right], \zeta(x, t)=4 \sqrt{2} \sqrt{c} k \sqrt{\alpha}$.
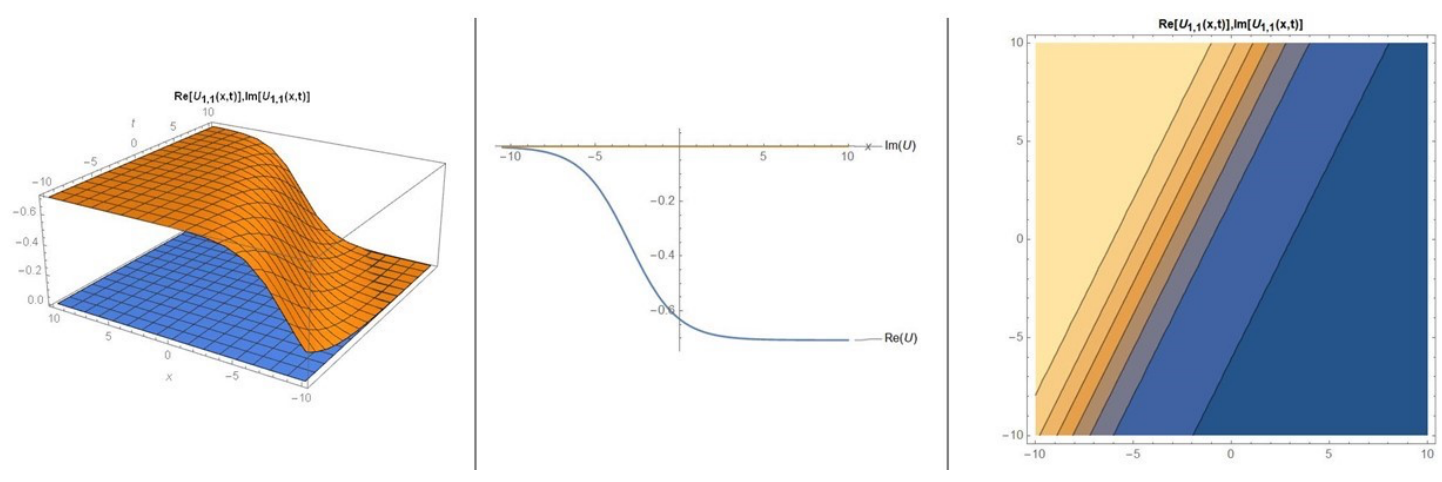

Figure 1: Three-dimensional, contour graphs of real and imaginary parts of Eqn. (15) for values $c=0, \alpha=$ $0.1, B_{0}=1, k=1, \mu=0.1, \beta=\frac{3}{2 \sqrt{2}}, \lambda=0.948683, E E=0.75$ and two-dimensional graph $t=1$ 


\section{Family 2:}

$$
U_{1,2}(x, t)=\left(\frac{1}{2} i \sqrt{-1+c-8 c k^{2} \alpha \mu}+\frac{\frac{\zeta}{4} \mu\left(\lambda+\lambda \operatorname{Cos}[\kappa]+\sqrt{-\lambda^{2}+4 \mu} \operatorname{Sin}[\kappa]\right)}{\lambda^{2}-2 \mu+2 \mu \operatorname{Cos}[\kappa]}\right)
$$

where $\kappa(x, t)=(E E+\xi) \sqrt{-\lambda^{2}+4 \mu}$.

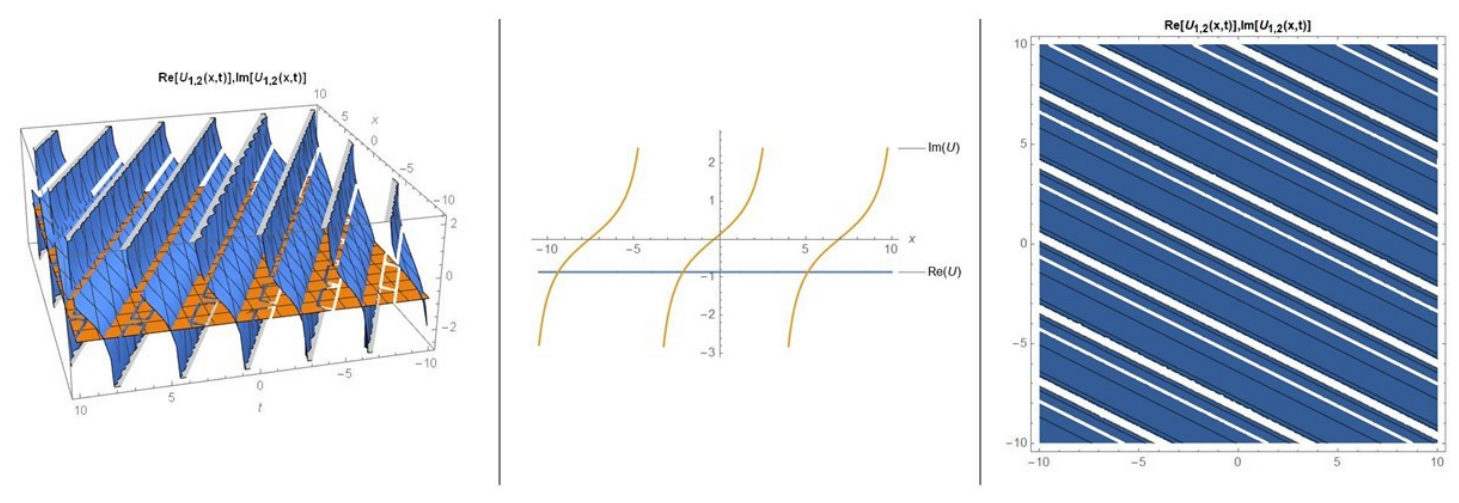

Figure 2: Three-dimensional, contour graphs of real and imaginary parts of Eqn. (16) for values $c=$ $-2, \alpha=1, B_{0}=3, k=-1, \mu=1, \beta=3 i \sqrt{3}, \lambda=\frac{\sqrt{13}}{2}, E E=0.65$ and two-dimensional graph $t=1$

\section{Family 3:}

$$
U_{1,3}(x, t)=\left(\frac{1}{2} i \sqrt{-1+c}-\frac{\zeta \lambda}{4\left(-1+e^{(E E+\xi) \lambda}\right)}-\frac{\sqrt{-(-1+c) B_{0}^{2}}}{2 B_{0}}\right)
$$
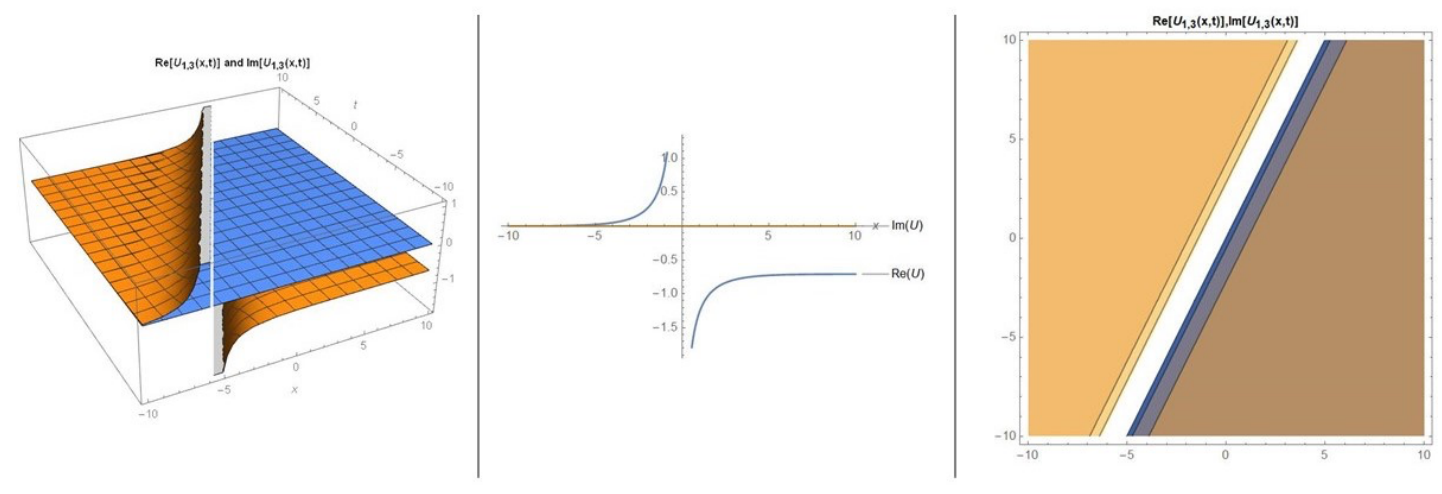

Figure 3: Three-dimensional, contour graphs of real and imaginary parts of Eqn. (17) for values $c=\frac{1}{2}$, $\alpha=1, B_{0}=3, k=1, \mu=0, \beta=3, \lambda=\frac{1}{\sqrt{2}}, E E=0.65$ and two-dimensional graph $t=1$ 


\section{Family 4:}

$$
U_{1,4}(x, t)=\frac{1}{2}\left(\zeta \lambda\left(1-\frac{2}{2+E E \lambda+\xi \lambda}\right)+i \sqrt{-1+c-8 c k^{2} \alpha \mu}-\frac{\sqrt{-(-1+c) B_{0}^{2}}}{B_{0}}\right) .
$$
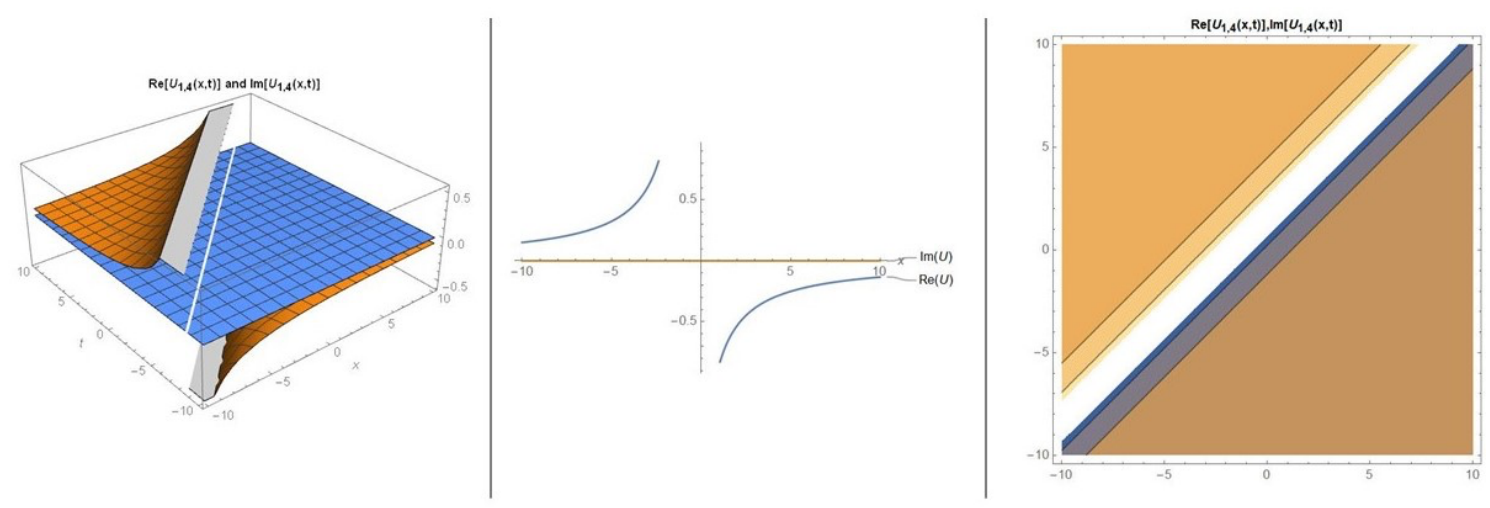

Figure 4: Three-dimensional, contour graphs of real and imaginary parts of Eqn. (18) for values $c=1$, $\alpha=1, B_{0}=3, k=1, \mu=1, \beta=\frac{3}{2 \sqrt{2}}, \lambda=2, E E=0.65$ and two-dimensional graph $t=1$

\section{Family 5:}

$$
U_{1,5}(x, t)=\frac{1}{2}\left(i \sqrt{-1+c}-\frac{\zeta}{2(E E+\xi)}-\frac{\sqrt{-(-1+c) B_{0}^{2}}}{B_{0}}\right) .
$$
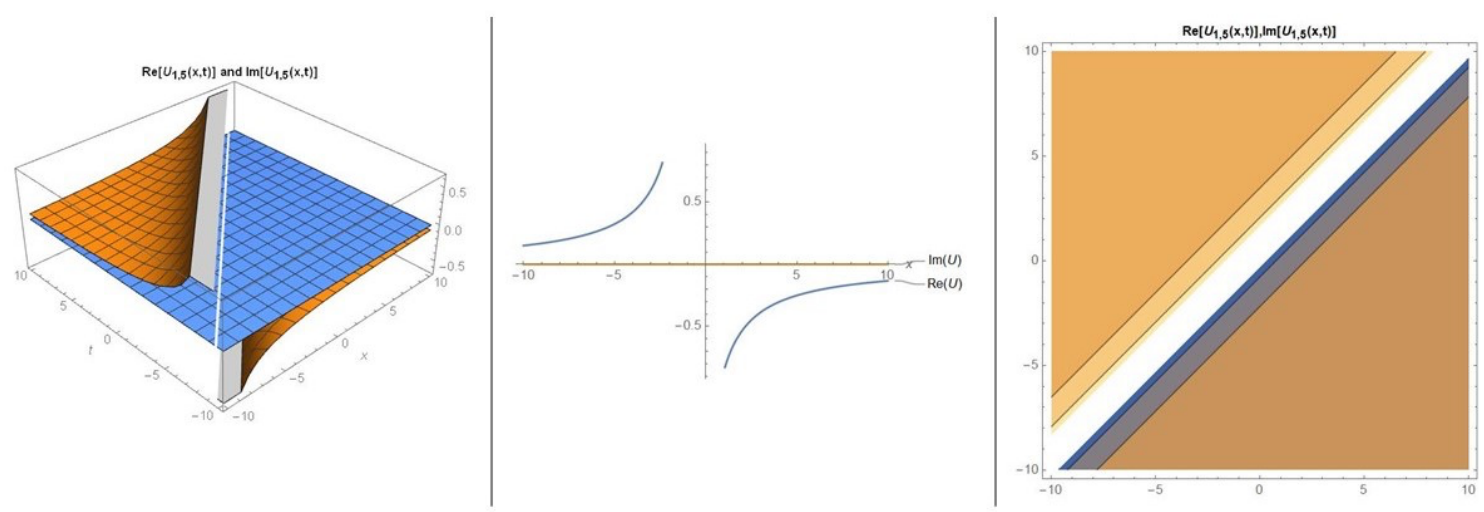

Figure 5: Three-dimensional, contour graphs of real and imaginary parts of Eqn. (19) for values $c=1$, $\alpha=1, B_{0}=3, k=1, \mu=0, \beta=\frac{3}{2 \sqrt{2}}, \lambda=0, E E=0.65$ and two-dimensional graph $t=1$ 


\section{Conclusions}

By Bruzón, M. S., et al., The solution function of the Buckley-Leverett equation has been studied byusing Lie theory. They converted the nonlinear partial differential equation into ordinary differential equation format with the help of transformation. Then they obtained the Jacobi Elliptic function as a solution function. When the solution functions obtained in our study are analyzed, it is seen that hyperbolic, trigonometric, and rational solution functions are obtained. In order to understand the physical meanings of the solutions in this study, two and threedimensional graphics were drawn with contour simulations. Mathematica software program was used to obtain all these numerical operations and to draw graphs. When the algebraic equation system is solved according to MEFM, the analyzed family cases are determined for the coefficients obtained, and the real and imaginary solution functions of the Buckley-Leverett equation are obtained. It has been seen that the method used in this study is a highly effective technique in obtaining analytical solutions of nonlinear partial differential equations.

\section{References}

[1] Sun, Y., New travelling wave solutions for Sine-Gordon equation, Journal of Applied Mathematics, 2014.

[2] Bulut, H., Akturk, T., Gurefe, Y., Traveling wave solutions of the $(N+1)$-dimensional sine-cosine-Gordon equation, American Institute of Physics Conference Proceedings, 1637(1), 145-149, 2014.

[3] Liu, C. S., Trial equation method and its applications to nonlinear evolution equations, Acta Physica Sinica., 54(6), 2505-2509, 2005.

[4] Shen, G., Sun, Y., Xiong, Y., New travelling-wave solutions for Dodd-Bullough equation, Journal of Applied Mathematics, 2013.

[5] Akturk, T., Bulut, H., Gurefe, Y., New function method to the $(n+1)$-dimensional nonlinear problems, An International Journal of Optimization and Control: Theories \& Applications, 7(3), 234-239, 2017.

[6] Pandir, Y., Gurefe, Y., Kadak, U., Misirli, E., Classification of exact solutions for some nonlinear partial differential equations with generalized evolution, Abstract and Applied Analysis, 2012, 16, 2012.

[7] Akturk, T., Bulut, H., Gurefe, Y., An application of the new function method to the Zhiber-Shabat equation, An International Journal of Optimization and Control: Theories \& Applications, 7(3), 271-274, 2017.

[8] Chen, Y., Yan, Z., New exact solutions of (2+1)-dimensional Gardner equation via the new sine-Gordon equation expansion method, Chaos, Solitons \& Fractals, 26(2), 399-406, 2005.

[9] Kudryashov, N.A., One method for finding exact solutions of nonlinear differential equations, Communications in Nonlinear Science and Numerical Simulation, 17, 2248-2253, 2012. 
[10] Sakar, M.G., Saldır, O., Akgül, A., A novel technique for fractional Bagley-Torvik equation, Proceedings of the National Academy of Sciences, India Section A: Physical Sciences, 89(3), 539-545, 2019.

[11] Sakar, M.G., Saldır, O., Improving variational iteration method with auxiliary parameter for nonlinear time-fractional partial differential equations, Journal of Optimization Theory and Applications, 174(2), 530-549, 2017.

[12] Ismael, H.F., Bulut, H., Baskonus, H.M., Gao, W., Newly modified method and its application to the coupled Boussinesq equation in ocean engineering with its linear stability analysis, Communications in Theoretical Physics, 72(11), 115002, 2020.

[13] Ismael, H.F., Bulut, H., Baskonus, H.M., W-shaped surfaces to the nematic liquid crystals with three nonlinearity laws,. Soft Computing, 25(6), 4513-4524, 2021.

[14] Ismael, H.F., Baskonus, H.M., Bulut, H., Abundant novel solutions of the conformable Lakshmanan-Porsezian-Daniel model, Discrete \& Continuous Dynamical Systems-S, 2020.

[15] Lingyu, M., Liao, X., Chen, Z., Zou, J., Chu, H., Li, R., Analytical solution of BuckleyLeverett equation for gas flooding including the effect of miscibility with constant-pressure boundary, Energy Exploration \& Exploitation, 37.3: 960-991, 2019.

[16] Bruzón, M.S., Marquez, A.P., Recio, E., Garrido, T.M., de la Rosa, D., Potential systems of a Buckley-Leverett equation: Lie point symmetries and conservation laws, Journal of Mathematical Chemistry, 1-10, 2020.

[17] Spayd, K.R., Shearer M., The Buckley-Leverett equation with dynamic capillary pressure, SIAM J. Appl. Math., 71, 1088-1108, 2012.

[18] Hassanizadeh, S. M., Gray, W. G., Mechanics and thermodynamics of multiphase flow in porous media including interphase boundaries, Advances in water resources, 13.4, 169-186, 1990.

[19] Uddin, S., Alam, N., Hossain, S.M.S., Samiu, H., Akbar, M.A., Some new exact traveling wave solutions to the (3+1)-dimensional Zakharov-Kuznetsov equation and the burgers equations via Exp-Expansion method, Frontiers of Mathematics and Its Applications, 1.1, 1-8, 2014. 